\title{
A rare cause of mediastinal expansion with a massive pleural effusion
}

\author{
Z Šubrt, A Ferko, Z Papík, Z Vacek, Z Sedláček
}

Postgrad Med J 2005;81:e18 (http://www.postgradmedj.com/cgi/content/full/81/961/e18). doi: 10.1136/pgmj.2005.036822

The authors present a case of a 53 year old woman, who was admitted to hospital because of an unusual cause of massive pleural effusion. During diagnostic examination the mediastinal propagation of the pancreatic pseudocyst was discovered as a complication of the chronic calcifying pancreatitis. The patient was operated on and the pseudocyst was resolved by Roux-en-Y cystiejunostomy. The diagnostics and treatment of this unusual pancreatic pseudocyst spreading is discussed.

P ancreatic pseudocysts are localised collections of the pancreatic juice surrounded by granulation tissue. They arise within the pancreas or in the peripancreatic space after an inflammatory process attributable to an acute and chronic pancreatitis or trauma. Pseudocysts develop in 5\%$10 \%$ of patients with and acute episode of pancreatitis and in $20 \%-40 \%$ patients with chronic pancreatitis. ${ }^{1}$ Sometimes they can have a very uncommon localisation.

\section{CASE REPORT}

A 53 year old woman presented with a four week history of dyspnea, cough, and chest pain located behind the sternum and radiating to the left clavicle and back. The patient also complained of mild epigastric discomfort after oral intake and of nine kilograms weight loss within the past month. Eleven years before the admission the patient had been treated for three episodes of severe acute pancreatitis of biliary aetiology. There was also heart ischaemic disease with myocardial infarction 11 years previously and arterial hypertension in the patient's history.

Examination showed dull percussion and weakened breath sounds on the chest right side. There was only mild increase of serum and urine amylase values in the laboratory findings (4.08 $\mu \mathrm{kat} / \mathrm{l}, 8.25 \mu \mathrm{kat} / \mathrm{l}$ respectively; normal serum value in our laboratory: $0.47-1.67 \mu \mathrm{kat} / \mathrm{l}$, urine concentration: 0 $7.67 \mu \mathrm{kat} / \mathrm{l})$, other laboratory tests were normal. ECG confirmed the history of the myocardial infarction but did not show any acute pathology.

Chest radiography showed a massive right sided pleural effusion. Repeated thoracocenteses yielded amount of 3900 $\mathrm{ml}$ of sanguineous fluid with a high amylase activity, $93.3 \mu \mathrm{kat} / \mathrm{l}$. Consecutive chest sonography confirmed residual pleural effusion and showed cystic expansion measuring 65$70 \mathrm{~mm}$ in diameter in the posterior mediastinum behind the left cardiac atrium. Bronchoscopy did not show any abnormality and TB was excluded.

Computed tomography of the chest and abdomen was performed and helped establishing the final diagnosis. CT scan showed the right sided pleural effusion but not pulmonary parenchyma infiltration or mediastinal lymphadenopathy. Cystic expansion $90 \times 70 \times 140 \mathrm{~mm}$ in the lower part of the posterior mediastinum between aorta and cardiac atrium communicating with pancreas was also found. Pancreatic changes were consistent with chronic calcifying pancreatitis without dilatation of the main pancreatic duct (figs 1,2). The definitive diagnosis was mediastinal extension of a pancreatic pseudocyst. An endoscopic retrograde cholangiopancreatography (ERCP) was not performed because the computed tomogram showed normal main pancreatic duct without dilatation. Surgical drainage was required. Peroperatively the pseudocyst was not adherent to the gastric wall and was located behind the left liver lobe straddling the oesophageal hiatus. The pseudocyst was successfully drained by Roux-en-Y cystjejunostomy. Postoperative course was without complications and the patient was discharged home after 12 days. The patient is well one month after the operation.

\section{DISCUSSION}

The mediastinal propagation of pancreatic pseudocyst is an uncommon complication of acute or chronic pancreatitis and only a few case reports have been published..$^{2}{ }^{5} 7$ It should be considered in patients with a history of alcoholism or pancreatitis. In our case the pseudocyst was a manifestation of the chronic calcifying pancreatitis so the amylases were not high. ${ }^{468}$

The most common symptoms are represented by chest pain, dyspnea, and weight loss. ${ }^{3}$ Abdominal complains can often be very mild. ${ }^{3}$ Some patients suffer from dysphagia. ${ }^{3} 910$

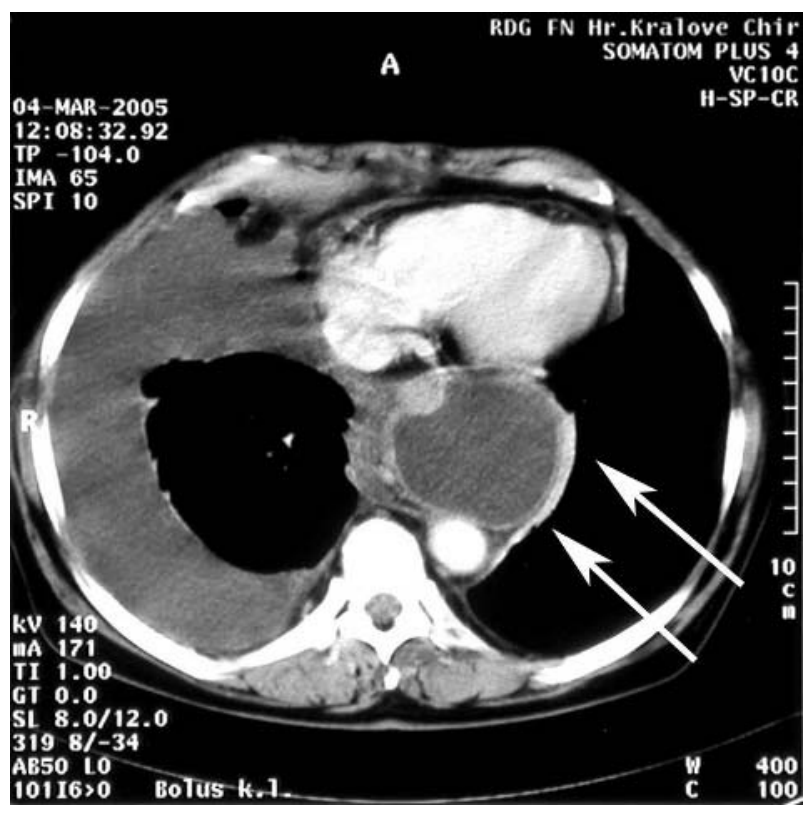

Figure 1 Contrast enhanced computed tomogram showing the right sided pleural effusion and an abnormal cystic expansion in the posterior mediastinum between aorta and cardiac atrium (arrows). 


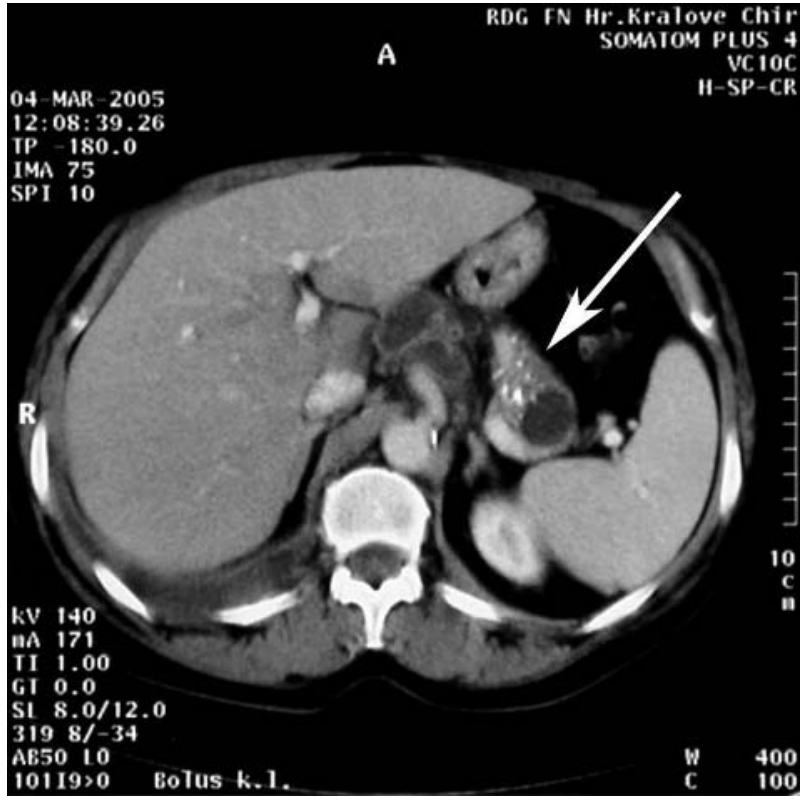

Figure 2 Contrast enhanced computed tomogram of the epigastrium showing chronic calcifying pancreatitis without dilatation of the main pancreatic duct and two pseudocyst formations in the pancreatic head and cauda (arrow).

The chest radiograph can sometimes show a mediastinal mass and often also a pleural effusion with high amylase activity. Contrast oesophagogram can show oesophageal displacement, which was not found in our case. The most important diagnostic method is contrast enhanced computed tomography that helps in differential diagnosis of mediastinal cystic masses ${ }^{11}$ and is able to show the relation to adjacent organs, especially diaphragm and digestive tube. It can also show the availability of the abdominal portion of the pseudocyst for endoscopical or surgical decompression. ERCP is also recommended and can represent the method of treatment of pseudocysts in chronic obstructive pancreatitis with strictures of the main pancreatic duct. ERCP was not performed in our case because the computed tomogram showed normal main pancreatic duct without dilatation. ${ }^{2}{ }^{11}$

Recent advances in inverventional radiology and endoscopy have changed the therapeutic approach to the pancreatic pseudocysts. Endoscopic pancreatic stenting combined with an octreotide pharmacological therapy can represent the option for treating selected cases with mediastinal pseudocysts in chronic pancreatitis with dilated main pancreatic duct. ${ }^{5}$
The gold standard of the treatment is an external or internal drainage of the pseudocyst. It can be performed endoscopically or surgically. Endoscopic or surgical cystgastrostomy is the method of choice for pseudocyst adherent to the posterior wall of the stomach. Other possibilities are cystduodenostomy or Roux-en-Y cystjejunostomy. ${ }^{2}{ }^{3}$ These procedures are safe, effective, and have acceptable morbidity and mortality. In our case the pseudocyst was not adherent to the gastric wall and was located behind the left liver lobe straddling the oesophageal hiatus. This situation was successfully managed by Roux-en-Y cystjejunostomy.

\section{Authors' affiliations}

Z Šubrt, A Ferko, Department of Field Surgery, Faculty of Military Health Sciences, University of Defence, Czech Republic and Department of Surgery, University Hospital, Charles University, Hradec Králové, Czech Republic

Z Papik, 2nd Department of Medicine, University Hospital, Charles University

Z Vacek, Z Sedláček, Department of Radiology, University Hospital, Charles University

Correspondence to: $M r Z$ Šubrt, Department of Field Surgery, Faculty of Military Health Sciences, University of Defence, Třebešská 1575, Hradec Králové, 500 01, Czech Republic; subrt@email.cz

Submitted 4 May 2005

Accepted 29 May 2005

\section{REFERENCES}

1 Goodley CD, Rattner DW. Pancreatic pseudocyst. In: Cameron JL, ed. In: Current surgical therapy. 6th ed. St Louis: Mosby, 1995:507-9.

2 Banks PA, McLellan PA, Ferzof SF, et al. Mediastinal pancreatic pseudocyst. Dig Dis Sci 1984;29:664-8.

3 Christensen NM, Demling R, Mathewson C Jr. Unusual manifestation of pancreatic pseudocysts and their surgical management. Am J Surg 1975:130:199-205

4 Dominguez-Munoz JE, Pieramico $O$, Buchler $M$, et al. Ratios of different serum pancreatic enzymes in the diagnosis and staging of chronic pancreatitis. Digestion 1993;54:231-6.

5 Kim DJ, Chung HW, Gham CW, et al. A case of complete resolution of mediastinal pseudocyst and pleural effusion by endoscopic stenting of pancreatic duct. Yonsei Med J 2003;44:727-31.

6 Pezzilli R, Talamini G, Gullo L. Behavior of serum pancreatic enzymes in chronic pancreatitis. Dig Liver Dis 2000;32:233-7.

7 Zeilender S, Turner MA, Glauser FL. Mediastinal pseudocyst associated with chronic pleural effusions. Chest 1990;97:1014-16.

8 Lankisch PG. The problem of diagnosing chronic pancreatitis. Dig Liver Dis 2003;35:131-4.

9 Maier W, Roscher R, Malfertheiner P, et al. Pancreatic pseudocyst of the mediastinum. Evaluation by CT. Eur J Radiol 1986;6:70-2

10 Woods CA, Foutch PG, Waring JP, et al. Pancreatic pseudocyst as a cause for secondary achalasia. Gastroenterology 1989:96:235-9.

11 Johnston RH, Owensby LC, Vargas GM, et al. Pancreatic pseudocyst of the mediastinum. Ann Thorac Surg 1986;41:210-12. 